\title{
NOVEL MUTATIONS OF THE G6PC GENE IN MALAYSIANS WITH GLYCOGEN STORAGE DISEASE 1a (GSD1a)
}

\author{
Abdul Rahman, A.A. ${ }^{1 a}$, Abdullah, I.S..$^{2 a}$, Teh, S.H. ${ }^{3 b}$, Khaidizar, F.D. ${ }^{4 c}$, Yap, S. ${ }^{5 d}$, \\ Keng, W.T. ${ }^{6 e}$, Ngu, L.H. ${ }^{7 e}$, Ong P.T. ${ }^{8 e}$, Chew H.B. ${ }^{9 e}$ and Mohamed, Z. ${ }^{10 a, f^{*}}$
}

\begin{abstract}
${ }^{\mathrm{a}}$ Genetics and Molecular Biology Unit, Institute of Biological Sciences, Faculty of Science, University of Malaya, 50603, Kuala Lumpur, MALAYSIA. Email: amirahassyiqqin@gmail.com¹; abdullah_ili@yahoo.co.uk ${ }^{2}$; zulq@um.edu.my ${ }^{10}$

${ }^{\mathrm{b}}$ Gene Express Sdn Bhd, 11, Mezzanine Floor, Jalan TP5, Taman Perindustrian UEP, 47620 Subang Jaya, Selangor, MALAYSIA. Email: serhuy@gmail.com ${ }^{3}$

${ }^{\mathrm{c}}$ Centre for Research in Biotechnology for Agriculture, University of Malaya, 50603, Kuala Lumpur, MALAYSIA. Email: fiqri@um.edu.my ${ }^{4}$

${ }^{\mathrm{d} D i v i s i o n}$ of Inherited Metabolic Disorders, Department of Paediatrics and University Malaya Medical Center, Faculty of Medicine, University of Malaya, 50603, Kuala Lumpur, MALAYSIA. Email: sufin.yap@nhs.net ${ }^{5}$

eDepartment of Genetics and Metabolism, Kuala Lumpur Hospital, 50586, Kuala Lumpur, MALAYSIA. Email: wtkeng@gmail.com ${ }^{6}$; ngulh@hotmail.com ${ }^{7}$

fInstitute of Advanced Studies, University of Malaya, 50603 Kuala Lumpur, MALAYSIA. Email: zulq@um.edu.my ${ }^{10}$
\end{abstract}

Corresponding author: zulq@um.edu.my

Received: $4^{\text {th }}$ Feb 2020

DOI: https://doi.org/10.22452/mjs.vol40no1.3

\begin{abstract}
Glycogen Storage Disease 1a is a rare autosomal recessive disorder caused by mutations in the glucose-6-phosphatase gene (G6PC) encoding glucose-6-phosphatase (G6Pase), a key enzyme for the maintenance of glucose homeostasis. Deficiency of G6Pase underlies this disease associated with lifethreatening hypoglycemia and growth retardation. To date, more than 110 mutations have be found worldwide. The aims of this study are to identify the mutations in G6PC gene in Malaysian GSD1a patients using standard molecular genetics methods and to determine the pathogenicity level of the novel mutations. We performed mutation screening for 21 GSD1a unrelated patients (Malay $n=14$; Chinese $n=7$ ) using Polymerase Chain Reaction (PCR) and DNA sequencing. Genomic DNA was extracted from patients' peripheral blood and all five G6PC exons were amplified using specific primers. Nine mutations were found, in which five mutations have been previously reported and four are potentially novel mutations (H52L, K76X, P113S and A346P). To obtain further evidence on the potential pathogenicity of the novel mutations, restriction enzyme assay and TaqMan genotyping assay were designed to investigate its allele frequency in a panel of healthy individuals that serves as the control population samples ( $n=50$ Malays, $n=50$ Chinese, $n=50$ Indians). Restriction enzymes $M$ seI and MboI were used to assay the K76X and P113S mutations, respectively. For the other two mutations (H52L and A346P), TaqMan genotyping assays was employed due to unavailability of a suitable restriction enzyme to distinguish between the normal and mutant sequences. Results obtained from both the restriction enzymes assays and the TaqMan assays showed that no mutant allele could be found in all 150 healthy individuals ( 300 alleles). In conclusion, four yet unreported mutations have been found in the Malaysian population, and these mutations are potentially novel pathogenic mutations. These finding provide support that the mutations spectrum of G6PC gene in Malaysia is heterogeneous, at least among the Chinese and Malay populations.
\end{abstract}


Keywords: Glycogen storage disease type 1a (GSD1a), glucose-6-phosphatase enzyme (G6Pase), Glucose-6-Phosphate catalytic subunit (G6PC).

\section{INTRODUCTION}

Glycogen Storage Disease type 1a (GSD1a; von Gierke disease; MIM \#232200) is an autosomal recessive metabolic disorder caused by mutations in glucose-6-phosphatase gene (G6PC). This disorder is caused by deficiencies of the microsomal glucose-6-phospatase (G6Pase) enzyme in the liver, kidney and intestinal mucosa as evidenced by excessive accumulation of glycogen in the organ (Chen and Burchil, 1999). G6Pase is the key enzyme for homeostasis (Lei et al., 1994) and play important roles for the final step of gluconeogenesis and glycogenesis. Deficiencies of this enzyme have been known to cause life-threatening hypoglycemia and growth retardation (Chen, 2001). Infants at 6 to 8 months of age typically present seizures and hepatomegaly as common symptoms. Other metabolic consequences associated with GSD1a include hyperuricemia, hyperlipidemia and lactic acidemia (Chou and Mansfield, 1999). Long term complications include hepatic adenomas that can develop into hepatocellular carcinoma (HCC) (Chen, 2001; Franco et al., 2005a), gout, renal disease and growth failure (Wang et al., 2011).

\section{Glucose-6-Phosphate catalytic subunit (G6PC) gene (GenBank} accession number: NG_011808.1) is the responsible gene encoding G6Pase that contributes to GSD1a. G6PC gene is a single copy gene which is located on chromosome 17q21 (Lei et al., 1994). Shelly et al. (1993) depicted that human G6PC gene spans $12.5 \mathrm{~kb}$ long and composes 5 exons (357- amino acids). Human G6Pase is extremely hydrophobic, contains nine putative membrane-spanning segments (Lei et al., 1993) with a molecular mass of about $40 \mathrm{kDa}$ (Peter et al., 2006). Topology analyses show that G6Pase contain multiple transmembrane domains that hold it within the endoplasmic reticulum (ER) membrane (Chou et al., 1998). The N-terminus of G6Pase is localized in the ER lumen and its C-terminus located in the cytoplasm (Pan et al., 1998). It is a primal enzyme for endogenous glucose production in specific organ, catalyzing the hydrolysis of G6P to glucose and inorganic phosphate (Chou et al., 2010).

The annual incidence of GSD1a is around 1/100,000 birth (Froissart et al., 2011) and the prevalence is currently not well described. To date, more than 111 different germline mutations have been reported and recorded in Human Gene Mutation Database (HGMD, http://www.hgmd.org). Over 550 unrelated patients affected with GSD 1a have been studied worldwide and all mutations found in the G6PC gene thus far are small gene alterations (Froissart et al., 2011). The most frequently found mutations are missense mutations at 64\% (Rake et al., 2000; Janecke et al., 2001). Some of the mutations are found at a higher frequency such as the R83C and Q347X mutations that were found at $33 \%$ and $18 \%$ respectively in the Caucasian population (Ekstein et al., 2004). An even higher frequency of R83C mutation was found in Jewish patients (98\%) (Froissart et al., 2011). Other common population-specific mutations include R83H in the Chinese population (Lei et al., 1995), and R83C and R170Q in the Tunisian population (Barkaoui et al., 2007). 
In this study we investigated the involvement of the $G 6 P C$ gene in a cohort of multi-ethnic Malaysian GSD1a patients. We resorted to using DNA-based genetic analysis techniques, as this avoids having to implement the invasive liver biopsy as well as facilitating screening of additional family members (Zheng et al., 2014).

\section{MATERIALS AND METHODS}

\subsection{Patients and control subjects}

Patients diagnosed with GSD1a attending University Malaya Medical Centre, UMMC and Kuala Lumpur Hospital, HKL were recruited for this study. In total we analyzed DNA from 42 individuals (30 patients and 12 family members) representing 28 unrelated families. Of these 30 patients, 22 were Malay, 7 were Chinese. The ethnicity of one remaining patient could not be determined as it was not clearly stated. All samples were obtained with the patients' and their families' informed consent, and this study has received the approval of the Medical Ethics Committee University Malaya Medical Centre reference number: UMMC MEC 2012/908.27. DNA from a panel of 150 healthy control individuals (50 Malays, 50 Chinese and 50 Indians as representative of three major races in Malaysia) were also included for analysis (see section $R E$ assay and TaqMan).

\subsection{Genomic DNA extraction}

Genomic DNA from the patients and controls were isolated from the peripheral blood leucocytes using QIAamp DNA extraction kit (QIAgen, USA) according to the manufacturer's instruction (QIAgen, USA). The quantity and quality of extracted DNA were then measured by DNA spectrophotometer (Implen Nanophotometer).

\subsection{Mutation Screening}

All five exons of the G6PC gene (GenBank accessionNG_011808.1) were PCR amplified for analysis using primer sets as previously reported in the literature (Angaroni et al., 2004; Lei et al., 1993). Each PCR reaction was performed in a total volume of $25 \mu 1$ that contained sterile distilled water, $1 \mathrm{X}$ PCR buffer, $1.5 \mathrm{mM} \mathrm{MgCl} 2,200 \mu \mathrm{M}$ of each dNTP, 1U Taq DNA polymerase (Eurax, Poland), $10 \mu \mathrm{M}$ of each forward and reverse primer and 50-100ng/ $\mu$ of DNA. PCR program used was $95^{\circ} \mathrm{C}$ for 5 min, 30 cycles of $95^{\circ} \mathrm{C}$ denaturation for $1 \mathrm{~min}$, specific annealing temperature for each primer set $(60$ $65^{\circ} \mathrm{C}$ ) for $1 \mathrm{~min}$ and extension $72^{\circ} \mathrm{C}$ for 1 min followed by a final extension step of $72^{\circ} \mathrm{C}$ for $5 \mathrm{~min}$. The molecular weights of PCR amplicons was confirmed with $1 \%(w / v)$ agarose gel electrophoresis. For sequencing, PCR products were purified either by gel extraction procedures or using direct PCR purification kits (QIAgen, USA) according to the manufacturers' instructions. Automated DNA sequencing was performed using BigDye Terminator Cycle Sequencing kit (Applied Biosystems, USA) on the 3130xl Genetic Analyzer (Applied Biosystems, USA).

\subsection{Sequence analysis and mutation characterization}

The sequences of each exons of G6PC gene were analyzed by comparison with the reference sequence (GenBank accession number: NG_011808.1). Mutations found were cross checked with G6PC mutations listed in the Human Gene Mutation 
Database (http://www.hgmd.cf.ac. uk/ac/index.php) for confirmation of pathogenicity. For mutations that are yet unreported as pathogenic, screening assays was designed to determine if the mutation is a mere polymorphism, in which it would be expected to appear at a higher frequency in the population compared to a pathogenic allele. Whenever possible, a restriction enzyme (RE) based assay would be used. Alternatively, when an RE based assay is not feasible, a TaqMan probebased assay will be utilized.

\subsection{Mutation screening of the control population sample}

Mutations that either creates or abolishes a RE cutting site may be screened using appropriately designed restriction enzyme based assays. DNA samples from the patient (positive control) and samples representing the general population are used for PCR amplification of the desired fragment spanning the mutation region. Following PCR, the products were then subjected to digestion using appropriate $\mathrm{RE}$ (done according to manufacturer's instructions), and the digestion results are determined by agarose gel electrophoresis.

In the present study, mutations c.226 $\mathrm{A}>\mathrm{T}$ in exon 1 and c. $337 \mathrm{C}>\mathrm{T}$ in exon 2 may be assayed using $M s e I$ (New England Biolabs, UK) and $M b o \mathrm{I}$ (New England Biolabs, UK) enzymes, respectively. Figure 1 shows the amplified fragments and the position of restriction cut sites.

A)
1 caccctgaacatgtttgcatcaacctactggtgatgcacctttgatcaatacattttaga
61 caacgtggtttttgagtccaaagatcagggctgggttgacctgaatactggatacaggg
121 catataaaacaggggcaaggcacagactcatagcagagcaatcaccaccaagcctggaat
181 aactgcaagggctctgctgacatcttcctgaggtgccaaggaaatgaggATGGAGGAAGG
241 AATGAATGTTCTCCATGACTTTGGGATCCAGTCAACACATTACCTCCAGGTGAATTACCA
301 AGACTCCCAGGACTGGTTCATCTTGGTGTCCGTGATCGCAGACCTCAGGAATGCCTTCTA

MseI titaa 406

361 CGTCCTCTTCCCCATCTGGTTCCATCTTCAGGAAGCTGTGGGCAтTAAACTCCTTTGGGT

MseI t| taa 454

421 AGCTGTGATTGGAGACTGGCTCAACCTCGTCTTTAAGTGgtaagaaccatatagagagga

481 gatcagcaagaaaagaggctggcattcgctctcgcaatgtctgtccatcagaagttgctt

541 tccccaggctattcaggaagccacgggctactcatgcttccaacccctctctctgacttt

601 ggatcatctac

B) 1 tatctccctctcacacttctcccagccacccagttctcccttctagaggcaacatgtga

61 aatccttctcaggctacactcttcttgaaggtgtaggctttgggcaaaagcattcattca

121 gtaaccccagaaacttgttctgtttttccatagGATTCTCTTTGGACAGCGTCCATACTG

181 GTGGGTTTTGGATACTGACTACTACAGCAACACTTCCGTGCCCCTGATAAAGCAGTTCCC

MboI |gatc 258

241 TGTAACCTGTGAGACTGGACCAGgtaagcgtcccagccctgcagacagaagctgagtgg

301 acctcgtttacctgttatggatgaaactgaccttgaggggacatgaggagagccattcct

361 ttgtactttgtcatgctcttcaattggcacaaattaattcacttctgcaatactttcct

421 gaatagcacagtagtattggaaatctgcctattacagaacctggatggag

Figure 1. Restriction enzyme map for mutation detection assays. A) Position of MseI enzyme digestion for normal sequence of partial G6PC gene, PCR amplified using primers for Exon 1. MseI enzyme cuts the T|TAA sequence at positions 406 and 454, generating three fragments sizing 405, 48 and 158bp. The c.226 A>T mutation changes the $\mathrm{A}$ at position 455 to a $\mathrm{T}$ and abolishes the cut site, giving only fragments 405 and 206bps. B) Restriction enzyme map of $M b o \mathrm{I}$ enzyme for normal sequence of partial G6PC gene, PCR amplified using primers for Exon 2. Normal sequence length is $470 \mathrm{bp}$. The c. $337 \mathrm{C}>\mathrm{T}$ mutation changes the $\mathrm{C}$ at position 260 to a T, generating an MboI cut site, giving fragments of 213 and $257 \mathrm{bp}$ after digestion. Underlined sequence denote position of forward and reverse primers. Capitalized sequences denote coding (exonic) sequences 
PCR of the patients' samples and 150 healthy control donors comprising multiracial Malaysians $(\mathrm{n}=50$ Malays, $\mathrm{n}=50$ Chinese, $\mathrm{n}=50$ Indians) were performed using appropriate primers as previously described. One unit of the MseI or MboI enzymes was added to a mixture containing $1 \mathrm{X}$ of CutSmart NEbuffer and appropriate amount of distilled water to digest $10 \mu \mathrm{g}$ of PCR products. The reaction mixture was prepared in $1.5 \mathrm{ml}$ centrifuge tube with total reaction volumes of $20 \mu 1$. The reaction mixtures were incubated for 16 hours at $37^{\circ} \mathrm{C}$. Negative controls lacking the enzymes were prepared for comparison. Standard agarose gel electrophoresis procedures were subsequently carried out to resolve the digested products for band scoring and allele identification.

For mutations that do not alter any restriction site, screening for the presence of the mutation in the general population (control) was done using a TaqMan genotyping assay. Primers and probe's sequences were designed based on G6PC gene references sequence (GenBank accession number: NG_011808.1) using Primer Express software (Applied Biosystems, USA). Primers and probes utilizes MGB-NFQ as quenchers at the 3 'end. The PCR reaction was carried out using the TaqMan GTXpress Master Mix (ABI, Applied Biosystems) and analyzed on QuantStudio $^{\mathrm{TM}}$ 12K Flex Real-Time PCR System (Applied Biosystems, USA). Allele discrimination was performed by QuantStudio ${ }^{\mathrm{TM}} 12 \mathrm{~K}$ Flex software. Amplification for the H52L Assay is achieved with primers 5'AATGCCTTCTACGTCCTCTTCC3 'and 5'GAGTTTAATGCCCACAGCTTCC 3' (amplicon size: 63bp), while the normal and mutant probes were 5'VICATCTGGTTCCATCTTC-3' and 5'FAM-ATCTGGTTCCTTCTTC-3'.

For the A346P mutation, the assay was achieved with amplification primers 5'TGGCATCCGTCAGTGTCATC3' and

5'CTCCACATCTCTTACAACGACT TCT3' (amplicon size: 80bp), while the normal and mutant probes were 5 ' VICACTGCCTCGCCCAGGT-3' and 5'FAM-CTACTGCCTCCCCCAGGT3

\section{RESULTS}

The initial stages of mutation screening were carried out involving 30 patients, and of these, mutations were successfully detected in 21 patients (70\%) while the remaining 9 patients did not show any sequence variation in their G6PC coding sequences. In a total of 42 alleles screened, nine different mutations were identified and summarized in Table 1A. Of these, five of the mutations have been previously reported, while the other four are thought to be novel. The mutation with the highest frequency is c.648G $>\mathrm{T}$; L216L (Kajihara et al., 1995) which was found in $21(50 \%)$ out of 42 alleles of combined ethnicities. This mutation was mostly found in the Malay patients (17/28 alleles) while in the Chinese patients, it was detected in only 4 $(28.6 \%)$ out of 14 alleles. The second commonly found mutation in this study is c.248G>A; R83H (Lei et al., 1995) which was found in 7 out of 14 alleles in Chinese patients (Table 1B). 
Table 1. Frequency of mutant alleles found in Malaysian patients. The two alleles with highest frequencies in each ethnicity are indicated with bold prints (B).

A)

\begin{tabular}{|c|c|c|c|c|}
\hline \multirow[b]{2}{*}{ Patients } & \multicolumn{2}{|c|}{ Allele 1 } & \multicolumn{2}{|c|}{ Allele 2} \\
\hline & Nucleotide & Amino acid & Nucleotide & Amino acid \\
\hline $1 / \mathrm{M} / \mathrm{C}^{*}$ & c. $248 \mathrm{G}>\mathrm{A}$ & $\mathrm{R}^{8} 3 \mathrm{H}^{[1]}$ & c. $248 \mathrm{G}>\mathrm{A}$ & $\mathrm{R} 83 \mathrm{H}$ \\
\hline $2 / \mathrm{M} / \mathrm{C}$ & c. $248 \mathrm{G}>\mathrm{A}$ & $\mathrm{R} 83 \mathrm{H}$ & c. $648 \mathrm{G}>\mathrm{T}$ & $\mathrm{L} 216 \mathrm{~L}^{[2]}$ \\
\hline 3/F/M & c. $648 \mathrm{G}>\mathrm{T}$ & L216L & c. $706 \mathrm{~T}>\mathrm{A}$ & $\mathrm{W} 236 \mathrm{R}^{[3]}$ \\
\hline 4/F/C & c. $.518 \mathrm{~T}>\mathrm{C}$ & $\mathrm{L}_{173 \mathrm{P}^{[4]}}$ & c. $664 \mathrm{G}>\mathrm{A}$ & $\mathrm{G} 222 \mathrm{R}^{[5]}$ \\
\hline 5/-/C & c. $248 \mathrm{G}>\mathrm{A}$ & $\mathrm{R} 83 \mathrm{H}$ & c. $648 \mathrm{G}>\mathrm{T}$ & L216L \\
\hline 6/F/M & c. $648 \mathrm{G}>\mathrm{T}$ & L216L & c. $648 \mathrm{G}>\mathrm{T}$ & L216L \\
\hline 7/M/M & c. $155 \mathrm{~A}>\mathrm{T}$ & H52L & c. $155 \mathrm{~A}>\mathrm{T}$ & H52L \\
\hline $8 / \mathrm{F} / \mathrm{M}$ & c. $226 \mathrm{~A}>\mathrm{T}$ & K76X & c. $648 \mathrm{G}>\mathrm{T}$ & L216L \\
\hline 9/-/C & c.518T >C & L173P & c. $648 \mathrm{G}>\mathrm{T}$ & L216L \\
\hline $10 / \mathrm{M} / \mathrm{C}$ & c. $248 \mathrm{G}>\mathrm{A}$ & $\mathrm{R} 83 \mathrm{H}$ & c. $248 \mathrm{G}>\mathrm{A}$ & $\mathrm{R} 83 \mathrm{H}$ \\
\hline 11/M/M & c. $648 \mathrm{G}>\mathrm{T}$ & L216L & c. $648 \mathrm{G}>\mathrm{T}$ & L216L \\
\hline $12 / \mathrm{F} / \mathrm{M}^{\mathbf{b}}$ & c. $648 \mathrm{G}>\mathrm{T}$ & L216L & c. $648 \mathrm{G}>\mathrm{T}$ & L216L \\
\hline 13/F/M* & c. $226 \mathrm{~A}>\mathrm{T}$ & K76X & c. $1036 \mathrm{G}>\mathrm{C}$ & A346P \\
\hline $14 / \mathrm{M} / \mathrm{M}^{\mathrm{a}}$ & c. $155 \mathrm{~A}>\mathrm{T}$ & H52L & c. $155 A>T$ & H52L \\
\hline $15 / \mathrm{M} / \mathrm{M}^{\mathrm{b}}$ & c. $648 \mathrm{G}>\mathrm{T}$ & L216L & c. $648 \mathrm{G}>\mathrm{T}$ & L216L \\
\hline $16 / \mathrm{M} / \mathrm{M}$ & c. $648 \mathrm{G}>\mathrm{T}$ & L216L & c. $648 \mathrm{G}>\mathrm{T}$ & L216L \\
\hline $17 \mathrm{M} / \mathrm{M} *$ & c. $648 \mathrm{G}>\mathrm{T}$ & L216L & c. $648 \mathrm{G}>\mathrm{T}$ & L216L \\
\hline $18 / \mathrm{M} / \mathrm{C}^{*}$ & c. $648 \mathrm{G}>\mathrm{T}$ & L216L & c. $248 \mathrm{G}>\mathrm{A}$ & $\mathrm{R} 83 \mathrm{H}$ \\
\hline 19/F/M & c. $226 \mathrm{~A}>\mathrm{T}$ & K76X & c. $648 \mathrm{G}>\mathrm{T}$ & L216L \\
\hline $20 / \mathrm{F} / \mathrm{M}^{\mathrm{c}}$ & c. $648 \mathrm{G}>\mathrm{T}$ & L216L & c. $337 \mathrm{C}>\mathrm{T}$ & P113S \\
\hline $21 / \mathrm{M} / \mathrm{M}^{\mathrm{c}}$ & c. $648 \mathrm{G}>\mathrm{T}$ & L216L & c. $337 \mathrm{C}>\mathrm{T}$ & P113S \\
\hline
\end{tabular}

B)

\begin{tabular}{lll}
\hline & \multicolumn{2}{c}{ Frequency } \\
\cline { 2 - 3 } Mutation & Malay & Chinese \\
\hline H52L & 0.14 & - \\
K76X & 0.10 & - \\
P113S & 0.07 & - \\
W236R & 0.04 & - \\
A346P & 0.04 & - \\
L216L & $\mathbf{0 . 6 1}$ & 0.29 \\
R83H & - & $\mathbf{0 . 5 0}$ \\
L173P & - & 0.14 \\
G222R & - & 0.07 \\
\hline
\end{tabular}

Note:

a Patient 7 and 14 are siblings

${ }^{\mathrm{b}}$ Patient 12 and 15 are siblings

${ }^{c}$ Patient 20 and 21 are siblings

*Parents samples provided

${ }^{[1]}$ Lei et al., 1995

${ }^{[2]}$ Kajihara et al., 1995

${ }^{[3]}$ Lei et al., 1995

${ }^{[4]} \mathrm{Li}$ et al., 2007

${ }^{[5]}$ Stroppiano et al., 1999 
The four potentially novel mutations were H52L (c.155A>T), K76X (c.226A>T), P113S (c.337C>T) and A346P (c.1036G>C), and they were all found in Malay patients. To provide stronger support that the unreported mutations are indeed pathogenic, the presence of these mutations were determined in a population of 150 unrelated healthy control samples representing the three major Malaysian races (Malays; $n=50$, Chinese; $n=50, \quad$ Indian; $n=50$ ). Mutation screening was performed either via restriction enzyme assays or TaqMan genotyping assay. The presence of the c.226A $>\mathrm{T}$ and c. 337C $>\mathrm{T}$ can be distinguished from the normal sequence using $\mathrm{MseI}$ and $\mathrm{MboI}$ restriction enzymes respectively. The MseI enzyme cuts the normal sequence 5'-T $\downarrow$ TAA-3', generating fragments with molecular sizes of $48 \mathrm{bp}, 158 \mathrm{bp}$, and 405bp. The c.226A>T mutation abolishes one cutting site and this is evidenced by the presence of a 206bp fragment, which serves as an indicator of the presence of the c.226A $>\mathrm{T}$ mutant allele Figure 2A. The MboI enzyme, on the other hand was used to cut the c.337C $>\mathrm{T}$ mutant sequence at 5'GA $\downarrow$ TC-3' and will yield fragments of $213 \mathrm{bp}$ and 257bp. Normal sequence do not carry this cleavage site and will remain intact as a 470bp fragment Figure 2B. Upon completing these assays, we noted that none of the 150 healthy control samples carry any of the mutated alleles, thus lending further support that these mutations are pathogenic.

Screening of the population for the mutations c.155A $>\mathrm{T}$ and c.1036G $>C$ was achieved using the SNP TaqMan genotyping assay since the normal and mutant sequences cannot be discriminated using available enzymes. Figure $2 \mathrm{C}$ shows an example of an allele discrimination plot for c. $155 \mathrm{~A}>\mathrm{T}$ detection. The two blue dots represent the patients who are homozygous for the $\mathrm{T}$ alleles obtained from patients 7 and 14 (who are also siblings), while all other samples clustered within the homozygous A genotype, denoted by the red signals. For clarity of interpreting genotyping results, a "mock" heterozygote was introduced by mixing the mutant and normal samples, and this "mock" genotype is represented by the green signal. From our analysis, none of the 300 alleles of 150 healthy samples were of the mutant type. A similar conclusion was reached for the c. $1036 \mathrm{G}>\mathrm{C}$ genotyping assay and led us to conclude that both these mutations are pathogenic.

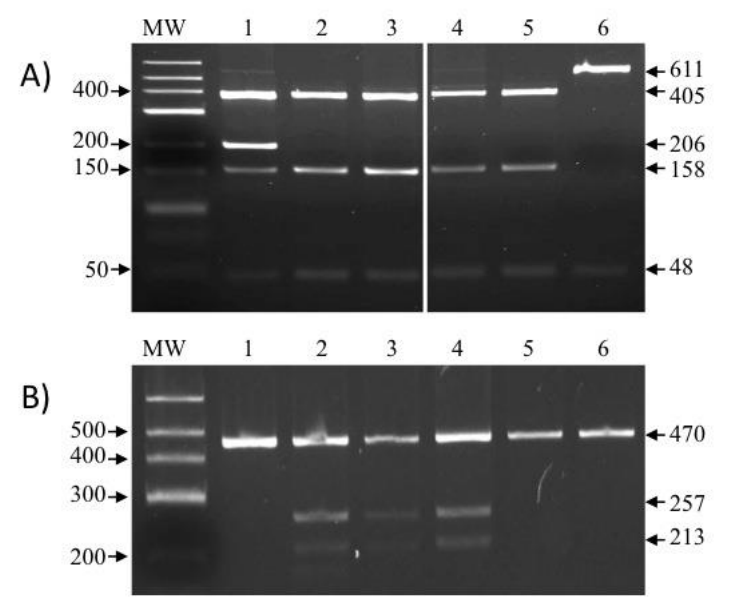




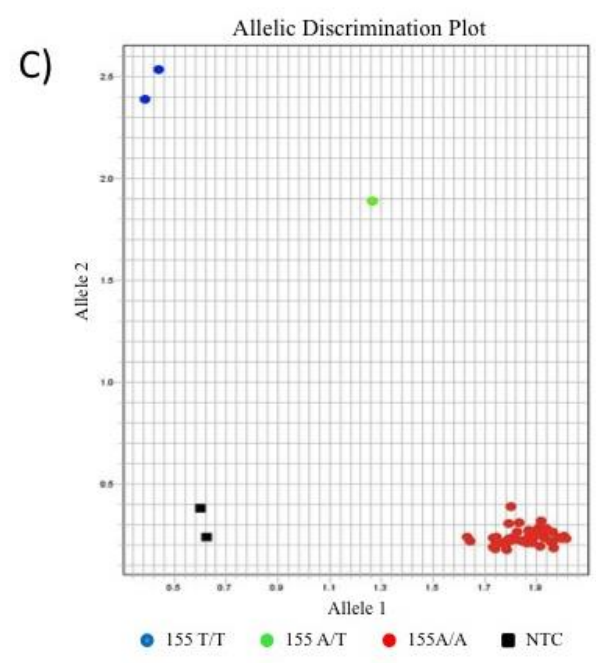

Figure 2. Example of mutation screenıng assays carried out on population samples. A) The c. 226A $>$ T mutation abolishes one $M s e$ I cutting site 5'-(T $\downarrow$ TAA-3') and this is evidenced by the presence of a 206bp fragment (Lane 1: +ve mutation control; Lanes 2-5: Test samples; Lane 6: Uncut). B) The c.337C > T mutation on generates an MboI cutting site (5'-GA $\downarrow$ TC3') which will yield fragments of 213bp and 257bp. (Lanes 1, 5 and 6: Test samples; Lanes 24: +ve mutation control). C) Allele discrimination plot for c.155A>T detection. Other than the patients' two blue dots (+ve mutation control) and the "mock" heterozygote allele (green dot), no mutant allela was detected in population test samples.

In silico prediction of the impact of amino acid substitution was made using PolyPhen-2, a freely available software (http://genetics.bwh.harvard.edu/pph2) that predicts the effects of amino acid changes based on a number of features comprising the sequence, phylogenetic and structural information characterizing the substitution. Both H52L and P113S were predicted to be damaging mutations with a score of 1.000, and comparison with homologous genes of more than 40 species show that the $\mathrm{H}$ and $\mathrm{P}$ amino acids are always conserved at their respective positions. On the other hand, A346P was categorized as benign with a score of only 0.205 , and multiple alignment with other homologous genes show that Ala in that position is not strictly conserved, with Met, His and Ser as alternatives (Figure 3). Analysis using SIFT also predict that changes from Ala to Pro is expected to be tolerated. (Table 2: polyphen and sift)

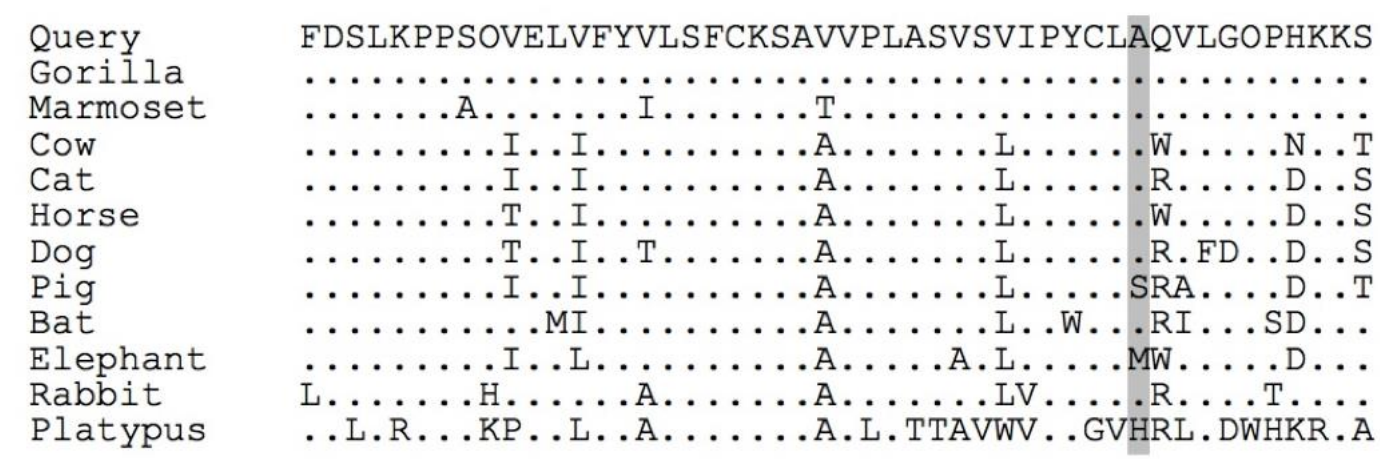

Figure 3. Sequence alignment showing partial conservation of Alanine at position 346 of the G6PC protein (shaded) 
Table 2. In silico prediction of the impact of amino acid substitution was made and compared two prediction programs Polyphen-2 and SIFT

\begin{tabular}{ccccccc}
\hline Mutation & \multicolumn{3}{c}{ PolyPhen-2 } & \multicolumn{3}{c}{ SIFT } \\
\cline { 2 - 6 } & Score & Prediction & $\begin{array}{c}\text { Specificity/ } \\
\text { Sensitivity }\end{array}$ & Score & Prediction & median \\
\hline A346P & 0.205 & BENIGN & $0.88 / 0.74$ & 0.31 & TOLERATED & 3.37 \\
P113S & 0.999 & PROBABLY & $0.09 / 0.99$ & 0.00 & DAMAGING & 3.17 \\
& & DAMAGING & & & & \\
\hline
\end{tabular}

\section{DISCUSSION}

GSD1a is the most common type of GSDs and to date more than 100 different germline mutations have been reported in the G6PC gene found to play a causal role in the pathogenesis of this disorder. In this study, 4 mutations that were yet unreported were identified in which one (K76X) was a protein truncation mutation where close to $80 \%$ of the protein is lost, and hence with deleterious effect. Such gross mutation are not expected to show any function, and in some cases, even the transcript may not be present because of elimination through a process called "Nonsense Associated mRNA Decay" (Baker and Parker, 2004). The three other mutations are amino acid substitutions, and thus require additional support to confirm their pathogenicity.

The $\mathrm{H} 52 \mathrm{~L}$ mutation resides in the first cytoplasmic loop of the glucose-6-phosphatase (G6Pase) enzyme which is not thought to require stringent conservation for maintaining structural requirements (Chou and Mansfield, 1999). However, a deleterious Q54P mutation located just 2 amino acids downstream have been reported in the Caucasian population (Trioche et al., 1999) and had been shown to completely abolished the G6Pase enzymatic activity (Shieh et al., 2002). A "probably damaging" effect with a score of 0.998 was predicted using the PolyPhen-2 analysis software, and this mutation was also not detected in all of the control samples representing the three major ethnicities in the country.

On the other hand, the P113S mutation is located in the luminal loop known to be important for maintaining the catalytic activity of the enzyme. Since a P113L mutation had been previously reported to result in complete inactivation of the G6Pase enzymatic activity (Shieh et al., 2002), it would be safe to assume that the P113S found in this study would show a similar effect. Also, P113S has been predicted to be "probably damaging" with a score of 0.999 by PolyPhen-2, and none of the control samples tested in this study carries this mutation.

Finally, the A346P located in the last transmembrane domain is also thought to be pathogenic as several other mutations found within this domain (eg. R295C, S298P, F322L, V338F, I341N and L345R) completely abolished G6Pase activity (Lei et al., 1995; Lei et al., 1995a; Shieh et al., 2002). While the pathogenicity of this mutation is supported by the fact that it is also absent in all control samples tested, predictions using PolyPhen-2 showed a contradictory "benign" status with a low score of 0.205 . A repeat prediction analysis using SIFT (Sorting Intolerant From Tolerant) software categorized this mutation as "Tolerated" (score: 0.31). Perhaps the definitive answer to the pathogenicity 
of this mutation may only be obtained through enzyme function studies and hence warrant further investigation.

The most common mutation found in this study is the silent mutation L216L which accounts for $50 \%$ of the total mutant alleles. This mutation was reported to be the major causative mutation for GSD1a in both the Japanese and Chinese population (Kajihara et al., 1995; Lam et al., 1998), while a more recent report included the Korean population in the list, with an allele frequency as high as $86.2 \%$ (Froissart et al., 2011; Kim, et al., 2020). The fact that this mutation was observed in both the Malay $(60.7 \%)$ and Chinese ethnicities (28.6\%) supports the notion that perhaps this is indeed a common mutation among Asian patients. Another common mutation found in the Japanese, Chinese and Korean populations is the $\mathrm{R} 83 \mathrm{H}$ mutation (Lei et al., 1995). While in the Chinese patients this mutation account for $50 \%$ of all the mutant alleles, however, we did not find this mutation in the Malay patients.

\section{CONCLUSION}

In conclusion, this study has successfully identified four novel G6PC mutations (H52L, K76X, P113S and A346P) and five reported mutations, and this represents the first G6PC gene mutation report for the Malaysian population. None of the 150 healthy control individuals carry the mutant alleles which lends strong support that these mutations are indeed pathogenic in nature and causative of this disorder. Future studies should be focused on functional characterization of the novel mutation in the G6Pase gene in order to increase our understanding of the GSD1a.

\section{ACKNOWLEDGEMENT}

We thank University Malaya Medical Centre and General Hospital, Kuala Lumpur for providing blood samples or DNA samples of GSD III patients; Assoc. Prof. Dr. Ng Ching Ching and Dr. Azlina binti Ahmad Annuar for providing DNA samples for population study; Centre for Research in Biotechnology for Agriculture (CEBAR), UM for contributing Sanger sequencing platform. This project was sponsored by UM Biotechnology \& Bioproduct Research Cluster (RG07112BIO) and Postgraduate Research Grant (PPP) - Research (PG2052014B)

\section{REFERENCES}

Angorani, C. J., de Kremer, R. D., Argaraña, Paschini-Capra, A. E., Giner-Ayala, A. N., Pezza, R. J., Pan, C. J and Chou, J. Y. (2004). Glycogen storage disease type 1a in Argentina: two novel glucose-6phosphatase mutations affecting protein stability. Molecular Genetic Metabolism, 83: 276-279.

Baker, K. E. and Parker, R. (2004). "Nonsense-mediated mRNA decay: Terminating erroneous gene expression". Current Opinion in Cell Biology. 16 (3): 293-299. doi:10.1016/j.ceb.2004.03.003. PMID 15145354.

Barkaoui, E., Cherif, W., Tebib, N., Charfeddine, C., Ben Rhouma, F., Azzouz, H., Ben Chehida, A., Monastiri, K., Chemli, J., Amri, F., Ben Turkia, H., Abdelmoula, M. S., Kaabachi, N., Abdelhak, S and Ben Dridi, M.F. (2007). Mutation spectrum of glycogen storage disease type Ia in Tunisia: implication for molecular diagnosis. Journal Inherited Metabolism Disorder, 30(6):989. 
Chen, Y. T \& Burchell, A. (1999).Glycogen storage diseases. In: Scriver C. R., Beaudet A. L., Sly W. S., Vale D (Eds.), The metabolic and molecular bases of inherited diseases, (7th ed.) (pp. 925-965). New York, NY: McGraw-Hill.

Chen, Y. T. (2001). Glycogen storage disease. In Scriver, C. R., Beaudet, A. L., Sly, W. S., Valle, D. (Eds.), The metabolic and molecular bases of inherited diseases, (8th Ed.) (pp 1521-1551). New York, NY: McGraw-Hill.

Chou, J. Y and Mansfield, B. C. (1999). Molecular Genetics of Type I Glycogen Storage Diseases. Trends Endocrinol Metabolism, 10: 104113.

Chou, J. Y., Hemrika, W., Annabi, B., Lei, K. J and Pan C. Y. (1998). Transmembrane topology of glucose-6-phosphatase. Journal of Biology and Chemistry, 273: 61446148.

Chou, J.Y., Jun, H.S. and Mansfield, B.C. (2010) Glycogen storage disease type I and G6Pase- $\beta$ deficiency: etiology and therapy. Nat. Rev. Endocrinol, 6:676-688.

Ekstein, J., Rubin, Berish.Y, Anderson, S.L., Weinstein, D.A., Bach, G., Abeliovich, D., Webb $\mathrm{M}$ and Risch, Neil. (2004). Mutation Frequencies for Glycogen Storage Disease Ia in the Ashkenazi Jewish Population. American Journal of Medical Genetics, 129A: 162-164

Franco, L. M., Krishnamurthy, V., Bali, D., Weinstein, D. A., Clary, B., Boney, A., \&d Kishnani, P. S. (2005a). Hepatocellular carcinoma in glycogen storage disease type 1a: A cases series. Journal of Inherited Metabolite Disorders, 28, 153-162.

Froissart, R., Piraud, M., Boudjemline, A. M., Vianey-Saban, C., Petit, R., Hubert-Buron, A., Eberschweiler,
P. T., Gajdos, V and Labrune. (2011). Glucose-6-phosphatase deficiency. Orphanet Journal of Rare Disorders, 6: 27.

Janecke, A. R., Mayatepek, E., \& Utermann, G. (2001). Minireview: Molecular genetics of type 1 glycogen storage disease. Molecular Genetic Metabolism, 73:117-125.

Kajihara, S., Matsuhashi, S., Yamamoto, K., Kido, K., Tsuji, K., Tanae, A., Fujiyama, S., Itoh, T., Tanigawa, K., Uchida, M., Setoguchi, Y., Motomura, M., Mizuta, T and Sakai, T. (1995). Exon Redefinition by a Point Mutation within Exon 5 of the Glucose-6-Phosphatase Gene Is the Major Cause of Glycogen Storage Disease Type Ia in Japan. Am. J. Hum. Genet, 57: 549-555.

Kim, Y., Choi, J., Lee, B., Kim, G., Kim, K., Yoo, H. (2020) Predominance of the c.648G > T G6PC gene mutation and late complications in Korean patients with glycogen storage disease type Ia. Orphanet J Rare Dis 15: 45 https://doi.org/ 10.1186/s13023020-1321-0

Lam, C. W., But, W. M., Shek, C. C., Tong, S. F., Chan, Y. S., Choy, K. W., Tse, W. Y., Pang, C. P and Hjelm, N. M. (1998). Glucose-6phosphatase gene (727G-->T) splicing mutation is prevalent in Hong Kong Chinese patients with glycogen storage disease type 1a. Clinical of Genetics, 53: 184-190.

Lei, K. J., Chen, Y. T., Chen, H., Wong, L. J., Liu, J. L., McConkie-Rosell, A., Van Hove, J. L. K., Ou, H. C., Yeh, N. J., Pan, L. Y and Chou, J. Y. (1995). Genetic basis of glycogen storage disease type Ia: Prevalent mutations at the glucose6-phosphatase locus. Am. J. Hum. Genet, 57: 766-771. 
Lei, K. J., Pan, C. J., Shelly,L. L., Liu, J. L. \& Chou, J. Y. (1994). Identification of mutations in the gene for glucose-6-phosphatase, the enzyme deficient in glycogen storage disease type la. Journal of Clinical Investigation, 93:19941999.

Lei, K. J., Shelly, L. L., Pan, C. J, Sidbury, J. B., \& Chou, J. Y. (1993). Mutations in the glucose-6phosphatase gene that cause glycogen storage disease type 1a. Science, 262:580-583.

Pan, C. J., Lei, K. J., Annabi, B., Hemrika, W and Chou, J. Y. (1998). Transmembrane Topology of Glucose-6-Phosphatase. Journal of Biology Chemistry, 273: 61446148.

Peter, G. A., Rake, S. J. P., Hasan, O., Akman., Salvatore, D. M. (2006). The Glycogen Storage Diseases and Related Disorders. Inborn Metabolic Diseases, 101-119.

PolyPhen-2: prediction of functional effects of human nsSNPs, http:// genetics.bwh.harvard.edu/pph2/

Rake, J.P., Berge, A.M., Visser, G. et al., (2000). Glycogen storage disease type Ia: recent experience with mutation analysis, a summary of mutations reported in the literature and a newly developed diagnostic flow chart. European Journal of Pediatrics, 159: 322330.

Shelly, L. L., Lei, K. J., Pan, C. J. et al., (1993). Isolation of the gene for murine glucose-6-phosphatase, the enzyme deficient in glycogen storage disease type 1A. Journal Biology Chemistry, 268: 2148221485.

Shieh, J. J., Terzioglu, M., Hiraiwa, H., Marsh, J., Pan, C. J., Chen, L. Y and Chou, J. Y. (2002). The molecular basis of glycogen storage disease type 1a. Journal of Biology Chemistry, 277: 50475053.

The Human Gene Mutation Database, http://www.hgmd.cf.ac.uk/ac/gene .php?gene $=$ G6PC.

Trioche, P., Francoual., Chalas, J., Capel, L., Bernard, O and Labrune, P. (1999). Identification of Three Novel Mutations (Q54P, W70X and T108I) in the Glucose-6phosphatase Gene of Patients with Glycogen Storage Disease Type Ia. Human Mutation, 14: 91.

Wang, J., Hong, C., Chung, N. L., Wuh, L. H., Yin, H. C., William, J. C., Lee, J. W., Zhang, V. W. (2013). Clinical application of massively parallel sequencing in the molecular diagnosis of glycogen storage diseases of genetically heterogeneous origin. Genetic in Medicine, 15(2): 106-114.

Zheng, X. B., Qian, L., Mei, L., Yu, J. (2014). Three novel mutation of the G6PC gene identified in chinese patients with glycogen storage disease type 1a. European Journal of Pediatrics. DOI 10.1007/s00431-014-2354-y 